1949 the National Academy of Sciences was complaining that the cash being thrown at oceanography was excessive. Finally, the money spawned new agencies, new companies and new university departments by the score, turning the United States in particular into a vast geophysical research and exploration machine the like of which had never been seen before.

The consequences were a wonder to behold. Exploration geophysics saw technical advance after technical advance, not least in the field of data processing. The more academic version of the subject went through a conceptual revolution with an impact greater than anything that had happened since catastrophism was overthrown nearly two centuries before. Geophysics entered the realm of Big Science with the International Geophysical Year, huge seismic arrays, deep-sea drilling and the monitoring of the Earth from space. And not least, geophysicists found themselves in politics - generally, for big projects require big pipers who tend to call big tunes, and specifically, because sciencederived political problems such as nuclear control demand scientific solutions such as explosion-earthquake discrimination.

All this and more (at least insofar as it relates to North America and Britain) is documented in meticulous detail with copious footnotes, charts and tables, which makes for some heavy reading at times. Those of a particular political persuasion will also find it irritating reading, for the viewpoint is hardly neutral. Bates and his colleagues make it quite clear that their aim is to document "the all-important role played by the innovator-capitalist operating in a free-enterprise system that has led to a major technology and service industry of great importance to the world's economic wellbeing". In short, the hard information comes in a politico-philosophical wrapper.

The result is as interesting to students of human nature as it is to geophysicists. The prevailing tone is one of old-fashioned technological optimism until, that is, we get to the 1970s and the rise of the "environmentalists". At this point Bates, Gaskell and Rice begin to come over as three rather nice old gents who have devoted their lives to the economic wellbeing of society (and have done pretty well out of it, as they would admit) but are now deeply puzzled, and perhaps even hurt, to find their basic values questioned by an unconventional enemy from within. They simply cannot comprehend the philosophical shift that has taken place; but then none of us yet knows just how deep or permanent it really is, or even whether it is a matter of genuine choice or historical imperative.

Peter J. Smith is Reader in the Department of Earth Sciences at the Open University, and editor of Open Earth.

\section{Talking physics}

\section{Ilya Prigogine}

\section{Physics as Natural Philosophy: Essays \\ in Honor of Laszlo Tisza on His \\ Seventy-fifth Birthday. \\ Edited by Abner Shimony and \\ Herman Feshbach. \\ MIT Press: 1983. Pp.448. \\ $£ 45, \$ 67$.}

DOCTORS Shimony and Feshbach are to be congratulated on having put together such a stimulating book to mark Professor Laszlo Tisza's seventy-fifth birthday. This gives me the opportunity to add my own congratulations. I remember my stay as Visiting Professor at Harvard in 1955, during which I had many discussions with him. We both were looking for a new path to take us beyond classical thermodynamics: even if our choice of routes was somewhat different, those discussions have been a source of inspiration for me.

The book contains five sections, each covering different aspects of Tisza's interests: the foundations of probability and thermodynamics; condensed matter physics; quantum mechanics and relativity; biological systems; and the history and philosophy of science. As a result the book provides a good introduction to some
Most physicists would, I think, consider Fourier's inequality as nothing but an expression of the Second Principle. This is the point of view taken, among others, by de Groot and Mazur in their well-known book on non-equilibrium thermodynamics. That book also contains an excellent chapter on magneto-thermoelectric effects; if the authors disagree with such authorities they should make explicit their reasons.

In the same vein, the article by Erwin Oppenheim, "Thermodynamics and Fluctuations in Nonequilibrium Systems", presents as a kind of novelty the fact that non-equilibrium fluctuation cannot be expressed in terms of the usual thermodynamic fluctuation theory. This however has been well known for more than ten years now. (Strangely enough, no references are given except to the work of Oppenheim in course of publication!)

Another point of contention lies in the interesting paper by David Layzer, "Quantum Mechanics, Thermodynamics, and the Strong Cosmological Principle"'. Here Layzer argues that the strong cosmological principle leads to an interpretation of the second law of thermodynamics that incorporates the "hierarchy" of order-generating processes. Even if one could agree with Layzer that our description of the physical Universe has to be in terms of distribution functions, rather than individual trajectories or wave functions, one is still very far from a theory of entropy increase or order generation. It is true that every theory of irreversibility has to be compatible with cosmology but it is doubtful if any cosmological principle by itself can lead to a microscopic theory of irreversible processes. One should not forget that in our expanding Universe we have both some processes which we can describe as reversible - at least at a very high accuracy - and other processes which are strongly irreversible. Of course, as Roger Penrose has suggested, it may be that we have to add some quantum gravity terms to explain irreversibility, but that is still not clear. I believe that irreversibility is a manifestation of the fact that we have to go from the initial representation of classical or quantum mechanics which is expressed in terms of canonical or unitary transformations, to a new representation in which the second law is incorporated and so to a new kind of transformation theory dealing with a class of non-unitary transformation. The same applies to general relativity.

Fortunately, there are many excellent articles in the book. I particularly liked those by J. M. Luttinger and Elliott $\mathbf{H}$. Lieb. Silvan S. Schweber's article is excellent and emphasizes the enduring truth that novel ideas often appear when points of view originating in one field of knowledge diffuse to another.

Ilya Prigogine is Regental Professor at the University of Texas, Austin, and a Professor at the Université Libre de Bruxelles. 